\title{
Posterior hypospadias
}

INSERM

\section{Source}

INSERM. (1999). Orphanet: an online rare disease and orphan drug data base. Posterior hypospadias. ORPHA:95706

Posterior hypospadias is a rare, non-syndromic, urogenital tract malformation characterized by an ectopic urethral meatus opening located in the posterior penis, the penoscrotal junction, the scrotum or the perineum, which often appears stenotic. The scrotum might appear bifid in severe cases and micropenis is not commonly associated. Urinary tract malformations, such as ureteropelvic junction obstruction, vesicoureteric reflux, pelvic or horseshoe kidney, crossed renal ectopia, renal agenesis, may be observed. 